\title{
Neuropsychiatric Disorders Among Aging Women: Assessing Risk Factors and Tailoring Treatment
}

\author{
Sarah B. Mathews ${ }^{1,2} \cdot$ C. Neill Epperson ${ }^{1,2,3}$
}

Published online: 19 October 2015

(C) Springer International Publishing AG 2015

\begin{abstract}
The older adult female population is fast growing, and sex differences exist for the majority of psychiatric and cognitive disorders affecting this group. Estradiol, with its variability during the reproductive years, particularly during the menopause transition, and its fall in the postmenopause, plays an important role in women's risks for neuropsychiatric changes. This review aims to review the evidence related to aging in women and common issues faced, including mood, anxiety, psychotic, and cognitive disorders. Important considerations regarding management of these disorders in aging women will also be addressed.
\end{abstract}

Keywords Cognition · Aging · Menopause $\cdot$ Women · Depression $\cdot$ Anxiety $\cdot$ Psychosis $\cdot$ Risk $\cdot$ Treatment

\section{Introduction}

The number of United States (US) citizens over the age of 65 is expected to be 72.1 million by 2030 , representing an overall

This article is part of the Topical Collection on Geropsychiatry and Cognitive Disorders of Late Life.

Sarah B. Mathews

sarah.mathews@uphs.upenn.edu

1 Department of Psychiatry, Perelman School of Medicine, University of Pennslyvania, 3535 Market Street, 3rd Floor, Philadelphia, PA 19104, USA

2 Penn Center for Women's Behavioral Wellness, Philadelphia, PA, USA

3 Department of Obstetrics and Gynecology, Perelman School of Medicine, University of Pennsylvania, Philadelphia, PA, USA increase of $87.5 \%$ from the 40 million reported in the 2010 census [1]. The graying of the US population will continue to have major ramifications for healthcare expenditures. That women outnumber men in the over 65 and particularly over 80 age categories highlights the importance of focusing on risk for neuropsychiatric conditions across the life span and particularly cognitive issues as women age.

Affective disorders, which are more common among women than men during the reproductive years, greatly impact the individual's quality of life in multiple domains including those related to professional development and earning potential. A recent analysis of economic burden related to mood disorders in the USA between 2005 and 2010 indicates that costs due to depressive disorders increased from 173.2 to 210.5 billion, with $50 \%$ of the costs attributable to loss of work productivity [2].

Medical disorders, such as autoimmune diseases [3], migraine $[4,5]$, thyroid disease [6, 7], and metabolic disorder [8] to name a few, affect women more often than men and are frequently comorbid with depression and anxiety. Similarly, women suffer from Alzheimer's disease (AD) at almost twice the rate of men, even when controlling for women's longer life expectancy [9]. Recent investigations support the notion that chronic stress is a risk factor for $\mathrm{AD}$ [10]. Whether this is particularly the case for women as they suffer from stressrelated psychiatric disorders more so than men has not been systematically studied [11]. The predominance of these disorders among women has important ramifications for healthcare providers who work with aging populations. The purpose of this review is to update the reader with respect to risk for neuropsychiatric and cognitive issues particularly in aging women. We will also highlight the need to consider the interaction between lifetime exposures to stress, reproductive hormones, medical illness, and the aging process when considering various treatment options. 


\section{Reproductive Aging and Impact on Brain Structure and Function: Brief Overview}

Although brain weight and cerebral blood flow decrease with aging, global neuronal cell loss does not typically occur. The cerebellum, the locus ceruleus, and the substantia nigra incur more cellular loss than areas such as the hypothalamus, pons, and medulla [12]. Decreases in the protective myelin and apoptosis lead to neuronal loss in these areas. Additionally, reductions in mitochondrial function, increases in oxidative stress, and the accumulation of ubiquitylated protein aggregates contribute to cell death [13]. Important signaling via neurotransmitter and neurotrophic pathways can be disrupted by these changes, and this may be particularly detrimental to important brain functions in vulnerable individuals.

Exposure to early or chronic stress, traumatic events, or medical use of glucocorticoids can directly or indirectly impact brain structure and function through effects on the hypothalamic pituitary adrenal (HPA) axis and brain regions involved in learning, memory, and affective modulation [14-17]. The stress hormone cortisol plays a necessary role in brain function, involving effects on the plasticity and survival of neurons. Nerve cells in areas of the brain important for regulating cognition and emotion may also be more vulnerable to neurotoxicity when exposed to prolonged and/or high glucocorticoid levels. With aging, hippocampal feedback control of the HPA axis decreases, producing a steady increase in circulating glucocorticoids [18]. Some evidence demonstrate that older women are at higher risk for dysfunction of this stress response than men [19]. Hormonal effects likely play a significant role in regulating the stress response even in younger women, with some evidence for protective effects of estrogen, which is revisited below [20].

In addition to stress, other psychosocial, behavioral, and health factors across the life span have been shown to impact the rate at which the brain ages. Brain health is adversely affected by sub-optimal health behaviors such as lifetime consumption of a high-fat diet [21], excessive alcohol use [22], and cigarette smoking [23]. When considering the aging brain, one must also evaluate the presence of medical conditions such as the metabolic syndrome [24], cardiovascular disease [25], pulmonary disorders [26], and autoimmune illnesses $[27,28]$ known to be highly comorbid with affective disorders and cognitive impairment/dementia. Hypertension is a well-known risk factor for sub-optimal cognition [29], but new reports from the large epidemiologic study of men and women known as the Systolic Blood Pressure Intervention Trial (SPRINT) may call into question the acceptability of our previous cutoffs for "normal" blood pressure [30].

For women, lifetime exposure to reproductive hormones and their characteristic fluctuations impacts markers of cellular aging [21-33], risk for dementia [34,
35•], and affective disorders [36•]. Greater lifetime exposure to estradiol is associated with longer telomeres and lower telomerase levels, suggesting that estradiol slows cellular aging [37]. While the relationship between estradiol and risk for dementia continues to be debated, numerous epidemiologic studies suggest a protective role [38•] and sustaining estradiol exposure during the fifth decade of life appears to be crucial to brain health among women who undergo a premature menopause [39••].

Unlike the central nervous system, that involves growth and development through much of the early life cycle, the aging of the ovary begins in utero, with significant decline in follicles containing germ cells. When the number of follicles becomes lowest, during the menopause transition, the production of the ovarian hormones estradiol and progesterone fluctuate dramatically and eventually dwindle to hypogonadal levels in the postmenopausal state. Ovarian hormones modulate neurotransmitters, cellular processes, and brain regions implicated in the pathogenesis of psychiatric and cognitive disorders [40, 41]. In animal models, fluctuating estradiol levels alter serotonin transmission in the amygdala and hippocampus, and in humans, studies of menopausal women undergoing estrogen treatment showed changes in mood as well as serotonin transmission relative to hormonal status [41]. In humans, memory has repeatedly been shown to be impaired by tryptophan (TRP) depletion, a manipulation that results in rapid reduction of the serotonin precursor tryptophan [42]. Reversal of acute TRP depletion-induced effects on brain activation in the "working memory network" of the bilateral dorsolateral prefrontal cortex and middle frontal gyrus has been observed with estradiol administration in menopausal women $[43 \cdot \bullet]$. Interestingly, there is some evidence from rodent [44] and human models [45] that estradiol administration may sensitize the aging female to the adverse effects of stress on cognition, perhaps via noradrenergic [46] or cholinergic effects $[39 \bullet \bullet$. Research in premenopausal women demonstrates an opposite effect, with high estradiol levels attenuating brain activation changes and negative mood response to psychosocial stress [20]. As stated previously, other evidence shows a more abnormal stress response, with more HPA reactivity, in older women, in lower estrogen states, compared with men [19].

Both estrogen and progesterone receptors are present in areas of the brain considered important for regulation of the stress response, emotion regulation, and memory functions, such as the hypothalamus, amygdala, hippocampus, and prefrontal cortex [47, 48], again brain regions impacted by chronic and/or traumatic stress as well as medical conditions requiring prolonged glucocorticoid treatment. Hence, factors intrinsic to women (i.e., characteristic fluctuations in reproductive hormones) are likely to interact with environmental factors occurring across the life span to promote risk or resilience for neuropsychiatric and cognitive disorders during old age. 


\section{Mood Disorders}

After puberty and prior to the onset of menopause, women are twice as likely to be affected by depression as men, but this sex difference decreases once women reach the postmenopausal years [49]. In contrast, the perimenopause represents a time of increased vulnerability for depression for women during the process of aging. Perimenopausal women are three to five times at greater risk for the development of a major depressive episode during perimenopause compared to premenopause [50-54]. Although a previous episode of depression has been shown to confer an increased risk for the development of depression during perimenopause [36•,51], women with no prior history of depression are two to three times likely to become depressed in the perimenopausal compared to their premenopausal state [51-53]. Some of the other independent risk factors for depression in perimenopause include poor sleep [51], stressful or negative life events [54], lack of employment [51], and lack of social support [54].

Hormonal changes occurring during menopause are also playing a significant role as evidenced by increased risk for depression with variability in estradiol levels (rather than absolute level) [36•, 55], surgical menopause [56], and the presence of hot flashes [57]. This is further supported by findings in younger women with higher risk of mood symptoms in the premenstrual and postpartum periods, when estrogen levels shift dramatically [58,59], and women with a history of PMS and PMDD have greater risk of perimenopausal depression [60]. One of the most recent findings published from the Penn Ovarian Aging Study [36•], a longitudinal investigation of women across the menopause transition, demonstrated that a more rapid rise in FSH prior to the final menstrual period, which is indicative of a shorter transition through menopause, predicted a decreased risk of depressive symptoms. Therefore, women who have a more prolonged perimenopause are likely at more risk for depression.

Furthermore, in double-blind, placebo-controlled trials, perimenopausal women receiving short-term 17 beta-estradiol transdermally had remission rates as high as $80 \%[61,62]$. In other randomized controlled trials, when estrogen was given to older, postmenopausal women with depression, there were no significant improvements in symptoms, suggesting a window of opportunity for estradiol's effects on brain function [63, 64]. Early findings from the Kronos Estrogen Early Prevention Study (KEEPS), a large, multi-site placebo-controlled study of early postmenopausal women treated with oral or transdermal estradiol and cyclic progesterone, showed benefit of oral estradiol on mood and neutral effects on cognition [65••]. That non-human primate research suggests that cyclic, but not consistent, estradiol is necessary to promote neuronal plasticity in the prefrontal cortex and maintenance of working memory indicates the importance of studying different hormone therapy schedules and preparations in human subjects [66].
Some risks for depression may remain in the early postmenopause [67•], but in general, the risk for depression decreases in the years following the final menstrual period. Age-related brain changes and particularly those related to the postmenopausal low-estrogen state are unlikely to increase risk for depressive disorders as might be expected. There may be a subset, however, of late-onset depression, which may be more directly related to cerebrovascular changes and neurodegeneration. Additionally, it seems that even though significant stressors such as medical illness, deaths of family members, financial instability, and social isolation can occur in older populations, the risk of depression remains lower. Resiliency and adaptive coping strategies are likely important protective factors.

When considering treatment for depressive disorder in older women, first-line treatments used for younger women remain standard practice. Women with perimenopausal depression have higher response rates to selective serotonin reuptake inhibitors (SSRIs) when directly compared to treatment with hormone replacement therapy [68]. There are cases requiring augmentation with hormone replacement, when only partial response is seen with antidepressant treatment and when other physical menopausal symptoms are present. Antidepressants such as the SSRIs have been shown to be effective for geriatric depression as well [69] and are typically tolerated in older women. Lower doses may be necessary to avoid side effects, and care is required regarding medication interactions, given high rates of polypharmacy in this population. Psychotherapy should also be considered, and studies demonstrate effectiveness of cognitive behavioral therapy in geriatric depression [70]. Barriers for older patients include availability of trained providers and acceptance of treatment.

There is very little research focusing on bipolar disorder in older female populations. Sex differences occur throughout the life cycle, with younger women having more risk for depressive and mixed episodes than men [71, 72] and women with bipolar disorder having increased risk for clinically significant premenstrual mood symptoms [73] as well as postpartum mania and psychosis [74]. Therefore, hormonal fluctuations are likely to be triggers for these mood symptoms, and this may be important for women in the perimenopause. Retrospective studies show that up to half of women with bipolar disorder report intense mood symptoms during the menopause transition and depression occurs more often than mania $[75,76]$. One recent cross-sectional survey of menopausal women demonstrated that women were more likely to have any mood symptoms during the late menopause transition and early postmenopause compared to late reproductive and early menopausal stages [77•]. In this study, FSH and estradiol levels and variability were not associated with the presence of mood symptoms but menopausal symptoms, including vasomotor symptoms, were associated with concurrent depressive symptoms among perimenopausal women with bipolar disorder. 
Rates for bipolar disorder in geriatric populations appear to be similar to those in younger adults, with $0.7 \%$ one-year prevalence in community samples [78]. In contrast to the pattern seen for major depressive disorder, prevalence of bipolar is similar in younger men and women but women over the age of 65 are more frequently diagnosed with bipolar disorder than men [79].

There are several treatment considerations for older women with bipolar disorder. Hormone therapy (HT) may be a consideration for adjunctive treatment of bipolar disorder in the perimenopause, particularly when depressive symptoms and sleep disruption due to vasomotor symptoms are present. Research has not yet been completed to evaluate the option of HT as a monotherapy; however, and therefore, mood stabilizers should remain the standard of care. Of course, caution should be used when using mood stabilizers in geriatric patients, who may have comorbid medical issues, greater risk for adverse events and side effects from medication, and potential medication interactions.

\section{Anxiety Disorders}

Although less research has focused on anxiety than depression in older women, anxiety disorders in this group are likely prevalent and require more attention. The incidence of anxiety disorders peaks in the fourth decade but, as seen with depression, may increase in frequency during the midlife for women. The majority of studies demonstrate an increase in anxiety symptoms during the menopause transition, especially in women with preexisting anxiety [80-84]. Risk for anxiety was elevated during perimenopause even for women with low levels of anxiety at baseline as well. Vasomotor symptoms have also been consistently associated with increased risk of anxiety during the menopause transition $[85,86]$. Some women experience a sense of anxiety with each hot flash. The symptoms described are most consistent with panic or generalized anxiety, but the associated risk of specific anxiety disorders has not been determined.

Similar to the mood disorders, anxiety disorders decrease in prevalence in older adults, including women, but here, women continue to be more at risk than men. Of older adults in community samples, 2 to $15 \%$ are affected by anxiety disorders [87], compared with $18 \%$ of younger adults [88]. Risk factors for anxiety in the elderly include chronic medical conditions, cognitive impairment, disability, and previous history of anxiety disorder [89]. In addition, one study involving postmenopausal women demonstrated that stressful life events increased risk for panic attacks [90]. In older adults, the most common anxiety disorders are generalized anxiety disorder and phobia, with panic disorder and obsessive-compulsive disorder declining in prevalence among the aged [87]. As during the premenopausal years, older women are at greater risk than men for most anxiety disorders [87].

Most antidepressants, which are first-line treatment options for anxiety disorders during the premenopausal years, remain effective for the treatment of anxiety during old age. Selective serotonin reuptake inhibitors have shown to be effective in older adults with anxiety disorders [91]. Augmentation with HT, particularly when vasomotor symptoms are present, would be appropriate. In geriatric populations, particular care is necessary when using benzodiazepines. These medications put older patients at risk for confusion, falls, and seizure related to withdrawal. Abuse and dependence of sedative hypnotics are also problematic, and female patients are at prescribed benzodiazepines more often than men, and older patients are more likely to receive benzodiazepines for prolonged periods of time [92]. While older women are more likely to use the medications as prescribed, they are still at risk for physical dependence and withdrawal [93]. Additionally, prolonged use of benzodiazepines may increase risk for dementia [94]. If benzodiazepines are used in older women, brief exposure with close monitoring is advised. Psychotherapy, particularly cognitive behavioral therapy, for anxiety disorders is also recommended, and there is growing evidence demonstrating effectiveness in older adults [91].

\section{Psychotic Disorders}

The well-known sex differences in prevalence, age at onset, and natural history of psychotic disorders suggest a possible role for reproductive hormones. In addition to earlier onset of psychosis/schizophrenia among men, studies have demonstrated that among women with schizophrenia, psychotic symptoms may be worse in the premenstrual phase, when estrogen levels decrease, and improve in phases with higher levels of estrogen $[95,96]$. Women with preexisting psychotic disorders are also at high risk for postpartum psychosis when estrogen levels fall [97]. Late-onset schizophrenia, with onset after the age of 40, is up to 10 times more common in women than men [98]. The onset is often between ages 45 and 50, which is typically concurrent with the early phases of the menopause transition. The onset for delusional disorder is later in women than in men as well, with a peak in the seventh decade [99]. There are few studies looking at risk for new onset psychosis specifically during menopause, however. Additionally, women with earlier onset schizophrenia do have a higher risk for worsening symptoms, with evidence for an increase in positive and negative symptoms during the menopause transition [100, 101].

In older women who are experiencing psychotic symptoms, treatment with an antipsychotic is still appropriate. Efficacy of antipsychotics may not be equivalent in the postmenopausal population, as younger women seem to 
have better treatment response at similar doses of antipsychotics compared with postmenopausal women [102]. Regardless of menopausal status, however, women may require lower doses of antipsychotics than men [103]. Older patients are likely to be more susceptible to the side effects of these medications, so the lowest effective dose should be utilized, and atypical antipsychotics should often be considered first prior to the typical antipsychotics. Close monitoring for metabolic changes, such as elevated glucose or lipid profile, as well as monitoring of electrocardiogram for QTC prolongation in some cases should be planned. For psychotic symptoms occurring during the perimenopause, treatment with adjunctive estrogen should also be considered. Both oral and transdermal estrogens have shown to be helpful as adjunctive treatments with antipsychotics in younger women $[104,105]$. One small study even showed evidence for benefit of a selective estrogen receptor modulator as an addition to an antipsychotic in treating psychotic symptoms [106]. Treatment of psychotic symptoms with hormone replacement therapy in the postmenopause, however, has demonstrated contradicting results. While hormonal treatment proved beneficial for reducing negative symptoms of schizophrenia when added to an antipsychotic in one study, it did not reduce risk for relapse of illness when used similarly in another study [107, 108].

\section{Cognitive Disorders}

Many women complain of changes in their cognitive function during the menopause, with the majority reporting worsening of verbal memory, as well as executive dysfunction and inattention $[109,110 \cdot]$. Up to $72 \%$ of menopausal women report some subjective memory impairment, and these symptoms are more likely to be associated with depressive symptoms and are more prevalent early in the menopause transition [111]. While some studies have demonstrated no objective changes in memory functioning during the perimenopause [111-113], a more recent report from the Penn Ovarian Aging Study indicates an objective decline in immediate and delayed verbal memory across the transition from premenopause to postmenopause [114•]. Additionally, findings from the Study of Women Across the Nation (SWAN), focusing on a more narrow window of the menopause transition, have shown that women entering menopause failed to improve as much on repeated tests of verbal memory compared to premenopausal women [115].

It is not entirely clear if women who have cognitive difficulties during the menopause transition are more at risk for cognitive impairment later in life. Although it is not likely that cognitive function returns to a woman's premenopausal baseline in postmenopause, she may adapt to and compensate for the symptoms with time. Some women do go on to develop mild cognitive impairment, with some objective evidence of decline, and a proportion of these women may develop dementia. Mild cognitive impairment is actually more prevalent in older males [116], but women are more at risk for several cognitive disorders, including the most common Alzheimer's disease [9]. Twenty percent of more women die from this disease than men, and this risk even remains after controlling for the effects of the female population's greater longevity [117].

Disparities in rates of cognitive disorders between men and women have led to focus on the role of estrogen in neuroprotection. This is supported by evidence from observational studies that treatment with HT during perimenopause decreases later risk for dementia [118-121]. There is likely a critical window for estrogen's positive effects, as women treated later in postmenopause have higher risk for development of dementia [35•] and women with dementia treated with hormone therapy have shown no improvements in cognitive symptoms or delaying the rate of progression of the disease [122]. Recent evidence from the KEEPS trial actually demonstrated no benefit for cognitive abilities of perimenopausal and early postmenopausal women with either the transdermal or oral preparations of estradiol; however, they were studied for a relatively brief period (4 years) and are not yet in the window of risk for MCI or $\mathrm{AD}[65 \cdot \bullet]$.

Perimenopausal and early postmenopausal women experiencing onset of cognitive difficulties may wish to consider a trial of HT, particularly if there is not contraindication for use and they are experiencing sleep disruption due to night sweats. Recently, psychostimulant medications used for attention deficit disorder have shown promising effects in treatment of perimenopause onset of executive function difficulties in specific. Small, placebo-controlled, crossover studies of atomoxetine [123] and lisdexamfetamine (LDX) [110•] reported both subjective and objective measures of improvement in executive functions and verbal recall, respectively. Caution should be used when prescribing these medications in older adults, due to cardiovascular risks for elevation of blood pressure and heart rate as well as interference with sleep and appetite. Abuse and dependence can also occur with use of psychostimulants, so these should be avoided in patients with a history of substance use disorders. Choice of treatment would depend on the patients' preference, the presence of other menopausal symptoms, and risks associated with either treatment for the individual. Preventative strategies for reducing risk for dementia include optimizing management of cardiovascular health, engaging in regular exercise, remaining socially active, and practicing cognitively challenging tasks [124]. For women with dementia, symptomatic treatment with cholinesterase inhibitors and NMDA receptor antagonists can provide some reductions in rate of cognitive decline [125]. Use of HT, however, for these women would not be recommended. 


\section{Conclusion}

Neuropsychiatric disorders are common among aging women, and factors such as stress exposures, comorbid medical conditions, and the hormonal changes of the perimenopause and postmenopause likely play a significant role in the development or exacerbation of symptoms in women. The relationship between these factors is complex, particularly when considering their individual and combined effects on the aging brain. Stress is associated with sub-optimal health behaviors that can directly undermine brain function but also contributes to risk for chronic medical conditions, neuropsychiatric disorders, and cognitive decline.

The discussion of risk for neuropsychiatric disorders in women has revolved around the reproductive hormones. Estradiol in specific has neuroprotective effects, but in aging women, the benefits of HT, with respect to effects on mood, psychotic symptoms, and cognition, remain a point of debate and investigation. Changing estradiol levels may adversely affect the stress response in older women. Whether estradiol enhances stress sensitivity in younger menopausal women who are proximal to their final menstrual period is not known, but in premenopausal women, the stress-induced effect of estradiol may be more protective [20]. Findings from the KEEPS trial provide evidence of the importance of initiating estradiol treatment in the early perimenopausalpostmenopausal period with respect to impact on mood and cognition $[65 \bullet \cdot$. Finally, for those women who undergo a premature menopause, the use of estradiol until their early $50 \mathrm{~s}$ is crucial to diminish their risk of dementia [38•].

Regarding treatment of neuropsychiatric disorders in older women, even if changes in hormonal status contribute to risk of symptoms, HT is not necessarily the most effective or safest option. Psychiatric medications and psychotherapies that target symptomatology often remain the first-line treatment. New research also suggests that psychostimulant treatment for the subset of menopausal women who experience significant executive function complaints may be helpful.

Women comprise the majority of individuals living into their ninth and tenth decades; therefore, a continued focus on risks and treatment of neuropsychiatric disorders in this group is imperative. Research on the effects of aging on neuropsychiatric conditions has focused primarily on depression and dementia, and an improved understanding of how and why these effects vary by gender is still needed. The fields of geriatric psychiatry and neurology would also benefit significantly from additional investigations regarding the impact of aging on anxiety disorders, bipolar disorder, and the psychotic disorders, particularly among women. The aging female population deserves a unique approach for management, with different risk factors for illness and treatment response compared not only with men but also with premenopausal women.

\section{Compliance with Ethics Guidelines}

Conflict of Interest Sarah B Mathews has no relevant disclosures to report. C Neill Epperson received research grant support from Shire and consults to Forest Laboratories. Epperson also has personal investments in Pfizer, Johnson and Johnson, Merck, Abbott, and Abbvie.

Human and Animal Rights and Informed Consent This article does not contain any studies with human or animal subjects performed by the author.

Support The writing of this manuscript was supported in part by funding from the National Institute of Mental Health (MH P50099910) and the National Institute on Aging (1R01AG048839).

\section{References}

Papers of particular interest, published recently, have been highlighted as:

- Of importance

•• Of major importance

1. Eden J. Maslow K, Le M, Blazer D, eds. Institute of Medicine, "The mental health and substance use workforce for older adults: in whose hands?" 2012.

2. Greenberg PE, Fournier AA, Sisitsky T, Pike CT, Kessler RC. The economic burden of adults with major depressive disorder in the United States (2005 and 2010). J Clin Psychiatry. 2015;76(2): 155-62.

3. Ngo ST, Steyn FJ, McCombe PA. Gender differences in autoimmune disease. Front Neuroendocrinol. 2014;35(3):347-69.

4. Saunders EF, Nazir R, Karnali M, Ryan KA, Evans S, Langenecker $\mathrm{S}$, et al. Gender differences, clinical correlates, and longitudinal outcome of bipolar disorder with comorbid migraine. J Clin Psychiatry. 2014;75(5):512-9.

5. Goulart AC, Santos IS, Brunoni AR, Nunes MA, Passos VM, Griep RH, et al. Migraines headaches and mood/anxiety disorders in the ELSA Brazil. Headache. 2014;54(8):1310-9.

6. Fjaellegaard K, Kvetny J, Allerup PN, Bech P, Ellervik C. Wellbeing and depression in individuals with subclinical hypothyroidism and thyroid autoimmunity - a general population study. Nord J Psychiatry. 2015;69(1):73-8.

7. Bauer M, Glenn T, Pilhatsch M, Pfennig A, Whybrow PC. Gender differences in thyroid system function: relevance to bipolar disorder and its treatment. Bipolar Disord. 2014;16(1):58-71.

8. Rhee SJ, Kim EY, Kim SH, Lee HJ, Kim B, Ha K, et al. Subjective depressive symptoms and metabolic syndrome among the general population. Prog Neuropsychopharmacol Biol Psychiatry. 2014;54:223-30.

9. Andersen K, Launer LJ, Dewey ME, Andersen K, Launer LJ, Dewey ME, et al. Gender differences in the incidence of $\mathrm{AD}$ and vascular dementia: the EURODEM studies. Neurology. 1999;53:1992-7.

10. Machado A, Herrera AJ, de Pablos RM, Espinosa-Oliva AM, Sarmiento M, Ayala A, et al. Chronic stress as a risk factor for Alzheimer's disease. Rev Neurosci. 2014;25(6):785-804.

11. Johansson L. Can stress increase Alzheimer's disease risk in women? Expert Rev Neurother. 2014;14(2):123-5.

12. Anglade $\mathrm{P}$, Vyas $\mathrm{S}$, Hirsch EC, Agid Y. Apoptosis in dopaminergic neurons of the human substantia nigra during normal aging. Histol Histopathol. 1997;12:603-10. 
13. Bishop NA, Lu T, Yankner BA. Neural mechanisms of ageing and cognitive decline. Nature. 2010;464:529-35.

14. Judd LL, Schettler PJ, Brown ES, Wolkowitz OM, Sternberg EM, Bender BG, et al. Adverse consequences of glucocorticoid medication: psychological, cognitive, and behavioral effects. Am J Psychiatry. 2014;171(10):1045-51.

15. Myers AJ, Williams L, Gatt JM, McAuley-Clark EZ, DobsonStone C, Schofield PR, et al. Variation in the oxytocin receptor gene is associated with increased risk for anxiety, stress and depression in individuals with a history of exposure to early life stress. J Psychiatr Res. 2014;59:93-100.

16. McEwen BS. Sex, stress and the brain: interactive actions of hormones on the developing and adult brain. Climacteric. 2014;17 Suppl 2:18-25.

17. Nemeroff $\mathrm{CB}$, Binder $\mathrm{E}$. The preeminent role of childhood abuse and neglect in vulnerability to major psychiatric disorders: toward elucidating the underlying neurobiological mechanisms. J Am Acad Child Adolesc Psychiatry. 2014;53(4):395-7.

18. Sapolsky M. Glucocorticoids, stress, and their adverse neurological effects: relevance to aging. Exp Gerontol. 1999;34:721-32.

19. Otte C, Hart S, Neylan TC, et al. A meta-analysis of cortisol response to challenge in human aging: importance of gender. Psychoneuroendocrinology. 2005;30:505-15.

20. Albert K, Pruessner J, Newhouse P. Estradiol levels modulate brain activity and negative responses to psychosocial stress across the menstrual cycle. Psychoneuroendocrinology. 2015;59:14-24.

21. Freeman LR, Haley-Zitlin V, Rosenberger DS, Granholm AC. Damaging effects of a high-fat diet to the brain and cognition: a review of proposed mechanisms. Nutr Neurosci. 2014;17(6):24151.

22. de la Monte SM, Kril JJ. Human alcohol-related neuropathology. Acta Neuropathol. 2014;127(1):71-90.

23. Chang RC, Ho YS, Wong S, Gentleman SM, Ng HK. Neuropathology of cigarette smoking. Acta Neuropathol. 2014;127(1):53-69.

24. Schrijvers EM, Witteman JC, Sijbrands EJ, Hofman A, Koudstaal PJ, Breteler MM. Insulin metabolism and the risk of Alzheimer disease: the Rotterdam study. Neurology. 2010;75:1982-7.

25. Nemeroff CB, Goldschmidt-Clermont PJ. Heartache and heartbreak - the link between depression and cardiovascular disease. Nat Rev Cardiol. 2012;9(9):526-39.

26. Lahousse L, Tiemeier H, Ikram MA, Brusselle GG. Chronic obstructive pulmonary disease and cerebrovascular disease: a comprehensive review. Respir Med. 2015.

27. Leyhe T, Müssig K. Cognitive and affective dysfunctions in autoimmune thyroiditis. Brain Behav Immun. 2014;41:261-6.

28. Sankowski R, Mader S, Valdés-Ferrer SI. Systemic inflammation and the brain: novel roles of genetic, molecular, and environmental cues as drivers of neurodegeneration. Front Cell Neurosci. 2015;9: 28.

29. Alipour H, Goldust M. The association between blood pressure components and cognitive functions and cognitive reserve. Clin Exp Hypertens. 2015;1:1-5.

30. Still CH, Craven TE, Freedman BI, Van Buren PN, Sink KM, Killeen AA, et al. Baseline characteristics of African Americans in the Systolic Blood Pressure Intervention Trial. J Am Soc Hypertens. 2015.

31. Cen J, Zhang H, Liu Y, Deng M, Tang S, Liu W, et al. Anti-aging effect of estrogen on telomerase activity in ovariectomised ratsanimal model for menopause. Gynecol Endocrinol. 2015;31(7): $582-5$.

32. Lin J, Kroenke CH, Epel E, Kenna HA, Wolkowitz OM, Blackburn E, et al. Greater endogenous estrogen exposure is associated with longer telomeres in postmenopausal women at risk for cognitive decline. Brain Res. 2011;1379:224-31.
33. Jacobs EG, Epel ES, Lin J, Blackburn EH, Rasgon NL. Relationship between leukocyte telomere length, telomerase activity, and hippocampal volume in early aging. JAMA Neurol. 2014;71(7):921-3.

34. Wroolie TE, Kenna HA, Williams KE, Rasgon NL. Cognitive effects of hormone therapy continuation or discontinuation in a sample of women at risk for Alzheimer disease. Am J Geriatr Psychiatry. 2015.

35. Shao H, Breitner JC, Whitmer RA, Wang J, Hayden K, Wengreen $\mathrm{H}$, et al. Hormone therapy and Alzheimer disease dementia: new findings from the Cache County Study. Neurology. 2012;79(18): 1846-52. This longitudinal study provides further evidence for a critical window for use of hormone therapy in order to reduce risk of dementia. Women who had started HT with 5 years of their last period had $30 \%$ less risk of developing Alzheimer's dementia than women who had not used HT, and those who started HT later in postmenopause, had even higher risk for developing Alzheimer's disease.

36. Freeman EW, Sammel MD, Boorman DW, Zhang R. Longitudinal pattern of depressive symptoms around natural menopause. JAMA Psychiatry. 2014;71(1):36-43. In this longitudinal study, women with no history of depression had higher risks of depressive symptoms in years before the final menstrual period and this decreased significantly by 2 years after the final menstrual period. For women with a history of depression, an increased risk of depressive symptoms remained present following the last menstrual period but was reduced compared to the years prior. Also, a rapid rise in FSH prior to the final menstrual period predicted a decreased risk of depressive symptoms.

37. Maki PM. Critical window hypothesis of hormone therapy and cognition: a scientific update on clinical studies. Menopause. 2013;20(6):695-709.

38. Ryan J, Scali J, Carrière I, Amieva H, Rouaud O, Berr C, et al. Impact of a premature menopause on cognitive function in later life. BJOG. 2014;121(13):1729-39. This large cohort study demonstrated that with both premature surgical menopause and premature ovarian failure, long-term negative effects on cognitive function can be found. Hormone therapy was not found to offset this risk.

39.• Dumas JA, Kutz AM, Naylor MR, Johnson JV, Newhouse PA. Estradiol treatment altered anticholinergic-related brain activation during working memory in postmenopausal women. Neuroimage. 2012;60(2):1394 403. This randomized placebo-controlled trial involved women taking stradiol while undergoing anticholinergic challenge, looking at cognitive effects and related functional neuroimaging. Estradiol treatment was found to modulate antimuscarinic- and antinicotinic-induced brain activity, suggesting that estradiol affected cholinergic system regulation of cognition-related brain activation.

40. Shanmugan S, Epperson CN. Estrogen and the prefrontal cortex: towards a new understanding of estrogen's effects on executive functions in the menopause transition. Hum Brain Mapp. 2014;35(3):847-65.

41. Amin Z, Canli T, Epperson CN. Effect of estrogen-serotonin interactions on mood and cognition. Behav Cogn Neurosci Rev. 2005;4(1):43-58.

42. Amin Z, Gueorguieva R, Cappiello A, Czarkowski KA, Stiklus S, Anderson GM, et al. Estradiol and tryptophan depletion interact to modulate cognition in menopausal women. Neuropsychopharm. 2006;31(11):2489-97.

43.•• Epperson CN, Amin Z, Ruparel K, Gur R, Loughead J. Interactive effects of estrogen and serotonin on brain activation during working memory and affective processing in menopausal women. Psychoneuroendocrinology. 2012;37(3):372-82. This randomized placebo-controlled study examined the combined effects 
of estradiol and serotonin on working memory, emotion processing and task-related brain activation in early postmenopausal women using functional magnetic resonance imaging (fMRI) both before and after short-term transdermal estradiol administration. Serotonergic effects directly mediated the impact of estrogen on brain activation during working memory and affective processing.

44. Shansky RM, Rubinow K, Brennan A, Arnsten AF. The effects of sex and hormonal status on restraint-stress-induced working memory impairment. Behav Brain Funct. 2006;7:2-8.

45. Newhouse PA, Dumas J, Wilkins H, Coderre E, Sites CK, Naylor $\mathrm{M}$, et al. Estrogen treatment impairs cognitive performance after psychosocial stress and monoamine depletion in postmenopausal women. Menopause. 2010;17(4):860-73.

46. Shansky RM, Bender G, Arnsten AF. Estrogen prevents norepinephrine alpha-2a receptor reversal of stress-induced working memory impairment. Stress. 2009;12(5):457-63.

47. Brinton RD. Estrogen-induced plasticity from cells to circuits: predictions for cognitive function. Trends Pharmacol Sci. 2006;30(4):212-22.

48. McEwen BS, Alves SE. Estrogen actions in the central nervous system. Endocr Rev. 1999;20(3):279-307.

49. Seedat S, Scott KM, Angermeyer MC, Berglund P, Bromet EJ, Brugha TS, et al. Cross-national associations between gender and mental disorders in the World Health Organization World Mental Health Surveys. Arch Gen Psych. 2009;66(7):785-95.

50. Schmidt PJ, Haq N, Rubinow DR. A longitudinal evaluation of the relationship between reproductive status and mood in perimenopausal women. Am J Psychiatry. 2004;161:2238-44.

51. Freeman EW, Sammel MD, Liu L, Gracia CR, Nelson DB, Hollander L. Hormones and menopausal status as predictors of depression in women in transition to menopause. Arch Gen Psych. 2004;61:62-70.

52. Freeman EW, Sammuel MD, Lin H, Nelson DB. Associations of hormones and menopausal status with depressed mood in women with no history of depression. Arch Gen Psych. 2006;63:375-82.

53. Cohen LS, Soares CN, Vitonis AF, Otto MW, Halow BL. Risk for new onset of depression during the menopausal transition: the Harvard study of moods and cycles. Arch Gen Psych. 2006;63: 385-90.

54. Bromberger JT, Matthews KA, Schott LL, Brockwell S, Avis NE, Kravitz HM, et al. Depressive symptoms during the menopausal transition: the Study of Women's Health Across the Nation (SWAN). J Affect Dis. 2007;103(1-3):267-72.

55. Avis NE, Crawford S, Stellato R, Longcope C. Longitudinal study of hormone levels and depression among women transitioning through menopause. Climacteric. 2001;4:243-9.

56. Sherwin BB, Gelfand MM. Sex steroids and affect in the surgical menopause: a double-blind, cross-over study. Psychoneuroendocrinology. 1985;10(3):325-35.

57. Freeman EW, Sammel MD, Lin H. Temporal associations of hot flashes and depression in the transition to menopause. Menopause. 2009;16(4):728-34.

58. Bloch M, Schmidt PJ, Danaceau M, Murphy J, Nieman L, Rubinow DR. Effects of gonadal steroids in women with a history of postpartum depression. Am J Psychiatry. 2000;157:924-30.

59. Schmidt PJ, Nieman LK, Danaceau MA, Adams LF, Rubinow DR. Differential behavioral effects of gonadal steroids in women with and in those without premenstrual syndrome. N Engl J Med. 1998;338:209-16.

60. Woods NF, Smith-DiJulio K, Percival DB, Tao EY, Mariella A, Mitchell S. Depressed mood during the menopausal transition and early postmenopause: observations from the Seattle Midlife Women's Health Study. Menopause. 2008;15:223-32.

61. Soares CD, Almeida OP, Joffe H, Cohen LS. Efficacy of estradiol for the treatment of depressive disorders in perimenopausal women: a double-blind, randomized, placebo-controlled trial. Arch Gen Psych. 2001;58:529-34.

62. Schmidt PJ, Nieman L, Danaceau MA, Tobin MB, Roca CA, Murphy $\mathrm{JH}$, et al. Estrogen replacement in perimenopauserelated depression: a preliminary report. Am J Obstet Gynecol. 2000;183:414-20.

63. Cohen LS, Soares CN, Poitras JR, Prouty J, Alexander AB, Shifren JL. Short-term use of estradiol for depression in perimenopausal and postmenopausal women: a preliminary report. Am J Psychiatry. 2003;160(8):1519-22.

64. Morrison MF, Kallan MJ, Ten Have T, Katz I, Tweedy K, Battistini. Lack of efficacy of estradiol for depression in postmenopausal women: a randomized, controlled trial. Bio Psychiatry. 2004;55:406-12.

65.• Gleason CE, Dowling NM, Wharton W, Manson JE, Miller VM, Atwood CS, et al. Effects of hormone therapy on cognition and mood in recently postmenopausal women: findings from the randomized, controlled KEEPS-cognitive and affective study. PLoS Med. 2015;12(6):e1001833. The KEEPS-Cog was a large, multisite randomized controlled study of hormone therapy in early postmenopausal women. Its findings suggest that hormone therapy did not alter cognitive abilities, but beneficial mood effects were found with oral estradiol, and not transdermal estradiol.

66. Young ME, Ohm DT, Janssen WG, Gee NA, Lasley BL, Morrison $\mathrm{JH}$. Continuously delivered ovarian steroids do not alter dendritic spine density or morphology in macaque dorsolateral prefrontal cortical neurons. Neuroscience. 2013;255:219-25.

67. Bromberger JT, Kravitz HM, Chang Y-F, Cyranowski JM, Brown $\mathrm{C}$, Matthews KA. Major depression during and after the menopausal transition: Study of Women's Health Across the Nation (SWAN). Psychol Med. 2011;41:1879-88. Recent findings from this large longitudinal study support previous research, showing that that women were two to four times more likely to experience major depression episode when they were perimenopausal or early postmenopausal. Effect of menopausal status was independent of history of major depression and annually measured upsetting life events, psychotropic medication use, vasomotor symptoms and serum levels of or changes in reproductive hormones.

68. Soares CN, Arsenio H, Joffe H, Bankier B, Cassano P, Petrillo LF, et al. Escitalopram versus ethinyl estradiol and norethindrone acetate for symptomatic peri- and postmenopausal women: impact on depression, vasomotor symptoms, sleep, and quality of life. Menopause. 2006;13(5):780-6.

69. Solai LK, Mulsant BH, Pollock BG. Selective serotonin reuptake inhibitors for late-life depression: a comparative review. Drugs Aging. 2001;18(5):355-68.

70. Francis JL, Kumar A. Psychological treatment of late-life depression. Psychiatr Clin North Am. 2013;36(4):561-75.

71. Altshuler LL, Kupka RW, Hellemann G, Frye MA, Sugar CA, McElroy SL, et al. Gender and depressive symptoms in $711 \mathrm{pa}-$ tients with bipolar disorder evaluated prospectively in Stanley Foundation bipolar treatment outcome network. Am J Psychiatry. 2010;167:708-15.

72. Benazzi F. The role of gender in depressive mixed state. Psychopathology. 2003;36:213-7.

73. Teatero ML, Mazmanian D, Sharma V. Effects of the menstrual cycle on bipolar disorder. Bipolar Disord. 2014;16(1):22-36.

74. Freeman MP, Smith KW, Freeman SA, McElroy SL, Kmetz GE, Wright R, et al. The impact of reproductive events on the course of bipolar disorder in women. J Clin Psychiatry. 2002;63:284-7.

75. Blehar MC, DePaulo Jr JR, Gershon ES, Reich T, Simpson SG, Nurnberger Jr JI. Women with bipolar disorder: findings from the NIMH genetics initiative sample. Psychopharmacol Bull. 1998;34(3):239-43. 
76. Marsh WK, Templeton A, Ketter TA, Rasgon NL. Increased frequency of depressive episodes during the menopausal transition in women with bipolar disorder: preliminary report. J Psychiatr Res. 2008;42(3):247-51.

77. Marsh WK, Gershenson B, Rothschild AJ. Symptom severity of bipolar disorder during the menopausal transition. Int J Bipolar Disord. 2015;3(1):35. This longitudinal study following menopausal women with bipolar illness demonstrated that the late menopause transition and early postmenopause, here compared to early perimenopause, are associated with greater mood symptom severity in bipolar spectrum women.

78. Weissman MM, Leaf PJ, Tischler GL, Blazer DG, Karno M, Bruce ML, et al. Affective disorders in five United States communities. Psychol Med. 1988;18(1):141.

79. Depp CA, Jeste DV. Bipolar disorder in older adults: a critical review. Bipolar Disord. 2004;6(5):343.

80. Bromberger JT, Assmann SF, Avis NE, Schocken M, Kravitz HM, Cordal A. Persistent mood symptoms in a multiethnic community cohort of pre- and perimenopausal women. Am J Epidemiol. 2003;158(4):347-56.

81. Avis NE, Stellato R, Crawford S, Bromberger J, Ganz P, Cain V, et al. Is there a menopausal syndrome? Menopausal status and symptoms across racial/ethnic groups. Soc Sci Med. 2001;52: 345-56.

82. Anderson D, Yoshizawa T, Gollschewski S, Atogami F, Courtney M. Relationship between menopausal symptoms and menopausal status in Australian and Japanese women: preliminary analysis. Nurs Health Sci. 2004;6:173-80.

83. Seritan AL, Iosif AM, Park JH, DeatherageHand D, Sweet RL, Gold EB. Self-reported anxiety, depressive, and vasomotor symptoms: a study of perimenopausal women presenting to a specialized midlife assessment center. Menopause. 2010;17(2): $410-5$.

84. Bromberger JT, Kravitz HM, Chang Y, Randolph Jr JF, Avis NE, Gold EB, et al. Self-reported anxiety, depressive, and vasomotor symptoms: a study of perimenopausal women presenting to a specialized midlife assessment center. Study of Women's Health Across the Nation. Menopause. 2010;20(5):488-95.

85. Juang KD, Wang SJ, Lu SR, Lee SJ, Fuh JL. Hot flashes are associated with psychological symptoms of anxiety and depression in peri- and post- but not premenopausal women. Maturitas. 2005;52(2):119-26.

86. Freeman EW, Sammel MD, Lin H, Gracia CR, Kapoor S, Ferdousi $\mathrm{T}$. The role of anxiety and hormonal changes in menopausal hot flashes. Menopause. 2005;12:258-66.

87. Bryant C, Jackson H, Ames D. The prevalence of anxiety in older adults: methodological issues and a review of the literature. $\mathrm{J}$ Affect Disord. 2008;109(3):233-50.

88. Kessler RC, Petukhova M, Sampson NA, Zaslavsky AM, Wittchen $\mathrm{H}$. Twelve-month and lifetime prevalence and lifetime morbid risk of anxiety and mood disorders in the United States. Int J Methods Psychiatr Res. 2013;21(3):169-84.

89. Vink D, Aartsen MJ, Schoevers RA. Risk factors for anxiety and depression in the elderly: a review. J Affect Disord. 2008;106(12):29-44.

90. Smoller JW, Pollack MH, Wassertheil-Smoller S, Barton B, Hendrix SL, Jackson RD, et al. Prevalence and correlates of panic attacks in the postmenopausal women: results from an ancillary study to the Women's Health Initiative. Arch Intern Med. 2003;163(17):2041-50.

91. Wetherell JL, Lenze EJ, Stanley MA. Evidenced-based treatment of geriatric anxiety disorders. Psychiatr Clin North Am. 2005;28: 871-96.

92. Olfson M, King M, Schoenbaum M. Benzodiazepine use in the United States. JAMA Psychiatry. 2015;72(2):136-42.
93. Ancill, RJ, Carlyle WW. Benzodiazepine use and dependence in the elderly: striking a balance. In Hallstrom (ed.) Benzodiazepine Dependence. Oxford University Press, 1993, 34-45.

94. Billoti De Gage S, Moride Y, Ducruet T, Kurth T, Verdoux H, Tournier M, et al. Benzodiazepine use and risk of Alzheimer's disease: case-control study. BMJ. 2014;349:g5205.

95. Bergmann N, Parzer P, Runnebaum B, Resch F, Mudt C. Estrogen, menstrual cycle phases, and psychopathology in women suffering from schizophrenia. Psychol Med. 2007;47:1427.

96. Seeman MV. Menstrual exacerbation of schizophrenia symptoms. Acta Psychiatr Scand. 2012;125(5):363-71.

97. Sit D, Rothschild AJ, Wisner KL. A review of postpartum psychosis. J Womens Health. 2006;15:352-68.

98. Howard R, Castle D, Wessley S, Murray R. Differences in lateand early-onset schizophrenia. Am J Psychiatry. 1993;150(5): 846-7.

99. Delusional disorder in women, Manschreck TC, Khan NL. Recent advances in the treatment of delusional disorder. Can J Psychiatry. 2006;51(2):114-9.

100. Sajatovic M, Donenwirth K, Sultana D, Buckley P. Admissions, length of stay, and medication use among women in an acute state psychiatric facility. Psychiatr Serv. 2000;51(10):1278-81.

101. Sajatovic M, Rosenthal MB, Plax MS, Meyer ML, Bingham CR. Mental illness and menopause: a patient and family perspective. J Gend Specif Med. 2003;6(2):31-4.

102. Goldstein JM, Cohen LS, Horton H, Lee S, Andersen M, Tohen A, et al. Sex differences in clinical response to olanzapine compared with haloperidol. Psychiatry Res. 2002;110(1):27-37.

103. Salokangas RK. Gender and the use of neuroleptics in schizophrenia. Schizophr Res. 2004;66(1):41-9.

104. Kulkarni J, de Castella A, Fitzgerald PB, Gurvich CT, Bailey M. Estrogen in severe mental illness: a potential new treatment approach. Arch Gen Psychiatry. 2008;65(8):955-60.

105. Kulkarni J. Oestrogen - a new treatment approach for schizophrenia? Med J Aust. 2009;190(4 Suppl):S37-8.

106. Kulkarni J, Gurvich C, Lee SJ, Gilbert H, Gavrilidis E, de Castella, et al. Piloting the effective therapeutic dose of adjunctive selective estrogen receptor modulator treatment in postmenopausal women with schizophrenia. Psychoneuroendocrinology. 2010;35(8): 1142-7.

107. Bergemann N, Mundt C, Parzer, Pakrasi M, EcksteinMannsperger U, Haisch S. Estrogen as an adjuvant therapy to antipsychotics does not prevent relapse in women suffering from schizophrenia: results of a placebo-controlled double-blind study. Schizophr Res. 2005;74(2-3):125-34.

108. Lindamer LA, Buse DC, Loh JB, Jeste DV. Hormone replacement therapy in postmenopausal women with schizophrenia, positive effect on negative symptoms. Biol Psychiatry. 2001;49:47-51.

109. Santoro N, Epperson CN, Mathews SB. Menopausal symptoms and their management. Endocrinol Metab Clin North Am. 2015;44(3):497-515.

110. Epperson CN, Shanmugan S, Kim DR, Mathews S, Czarkowski KA, Bradley J, et al. New onset executive function difficulties at menopause: a possible role for lisdexamfetamine. Psychopharmacology. 2015;232(16):3091-100. In this randomized placebo-controlled trial of lisdexamfetamine for cognitive complaints in menopausal women, this stimulant medication improved both subjective measures of executive function as well as objective measures of delayed verbal recall.

111. Woods NF, Mitchell ES, Adams C. Memory functioning among midlife women: observations from the Seattle Midlife Women's Health Study. Menopause. 2000;7(4):257-65.

112. Henderson VW, Guthrie JR, Dudley EC, Burger HG, Dennerstein L. Estrogen exposures and memory at midlife: a population-based study of women. Neurology. 2003;60(8):1369-71. 
113. Fuh L, Wang SJ, Lee SJ, Lu SR, Juang KD. A longitudinal study of cognition change during early menopausal transition in a rural community. Maturitas. 2006;53(4):447-53.

114. Epperson CN, Sammel MD, Freeman EW. Menopause effects on verbal memory: findings from a longitudinal community cohort. J Clin Endocrinol Metab. 2013;98(9):3829-38. Recent evidence from this longitudinal study of menopausal women indicates an objective decline in immediate and delayed verbal memory across the transition from pre- to postmenopause.

115. Greendale GA, Huang MH, Wight RG, Seeman T, Luetters C, Avis NE, et al. Effects of the menopause transition and hormone use on cognitive performance in midlife women. Neurology. 2009;72(21):1850-7.

116. Petersen RC, Roberts RO, Knopman DS, et al. Prevalence of mild cognitive impairment is higher in men. Neurology. 2010;75(10): 889-97.

117. Moschetti K, Cummings PL, Sorvillo F, Kuo T. Burden of Alzheimer's disease-related mortality in the United States, 1999-2008. J Am Geriatr Soc. 2012;60:1509-14.

118. Resnick SM, Henderson VW. Hormone therapy and risk of Alzheimer disease: a critical time. JAMA. 2002;288:2170-2.

119. Henderson VW, Benke KS, Green RC, Cupples LA, Farrer LA. Postmenopausal hormone therapy and Alzheimer's disease risk: interaction with age. J Neurol Neurosurg Psychiatry. 2005;76: $103-5$.

120. Whitmer RA, Quesenberry CP, Zhou J, Yaffe K. Timing of hormone therapy and dementia: the critical window theory revisited. Ann Neurol. 2011;69:163-9.

121. Shumaker S, Legault C, Kuller L, et al. Conjugated equine estrogens and incidence of probable dementia and mild cognitive impairment in postmenopausal women: Women's Health Initiative Memory Study. JAMA. 2004;291:2947-58.

122. Mulnard RA, Cotman CW, Kawas C, van Dyck CH, Sano M, Doody R, et al. Estrogen replacement therapy for treatment of mild to moderate Alzheimer disease: a randomized controlled trial. Alzheimer's Disease Cooperative Study. JAMA. 2000;283(8): 1007-15.

123. Epperson CN, Pittman B, Czarkowski KA, Bradley J, Quinlan DM, Brown TE. Impact of atomoxetine on subjective attention and memory difficulties in perimenopausal and postmenopausal women. Menopause. 2011;18(5):542-8.

124. Beydoun MA, Beydoun HA, Gamaldo AA, Teel A, Zonderman $\mathrm{AB}$, Wang Y. Epidemiologic studies of modifiable factors associated with cognition and dementia: systematic review and metaanalysis. BMC Public Health. 2014;14:643.

125. Schwarz S, Froelich L, Burns A. Pharmacological treatment of dementia. Curr Opin Psychiatry. 2012;25(6):542-50. 